\title{
Fast and reliable screening system to preselect candidate Dickeya solani Tn5 mutants in plant tissue-induced genes
}

\author{
Jakub Fikowicz-Krosko • Robert Czajkowski
}

Accepted: 19 April 2017 / Published online: 22 April 2017

(C) The Author(s) 2017. This article is an open access publication

\begin{abstract}
Here, we present a simple and fast screening method to preselect candidate Dickeya solani $\mathrm{Tn} 5 \mathrm{mu}-$ tants which carry transposon insertions in plant tissueinduced genes for the follow-up studies. The described method is faster and cost-effective in comparison to standard IVET, expression microarrays and RNAseq, and it does not require any specialized laboratory equipment and/or technical assistance. The Tn5 mutants are generated using mini-Tn5 transposon carrying inducible reporter gene (promoterless gus A coding for $\beta$-glucuronidase) and are screened for the $\beta$-glucuronidase positive phenotypes under non-inductive conditions with X-gluc as a glucuronidase substrate. The bacterial mutants negative in the first screen are then screened for $\beta$-glucuronidase phenotypes in the presence of plant tissues, viz. roots, stems and leaves, suspended in liquid bacterial growth medium supplemented with X-gluc in a 48-well microtiter plate assay. The mutants that are positive in the screen with plant tissues are selected for sequencing of the Tn5 insertion sites directly from bacterial genome. This method allows generation of a number of ready-to-use Tn5 mutants showing up-regulation by plant tissue which can be later selected for further studies. We used this method to evaluate interaction of $D$. solani IPO2222 (type strain) with bittersweet nightshade (Solanum dulcamara L.) and potato (Solanum tuberosum L.) tissues.
\end{abstract}

J. Fikowicz-Krosko · R. Czajkowski $(\bowtie)$

Department of Biotechnology, Intercollegiate Faculty of Biotechnology, University of Gdansk and Medical University of Gdansk, Antoniego Abrahama 58, 80-307 Gdansk, Poland e-mail: Robert.Czajkowski@biotech.ug.edu.pl
Keywords Gene fusion · Inducible reporter system . Screening $\cdot$ Promoterless gusA

The ability to cause infection in plants is a complex characteristic that occurs only in limited number of known bacterial species (Vidaver and Lambrecht 2004). Understanding the molecular background of pathogen adaptations which allows bacteria to invade and colonize plant tissues and/or subvert host metabolism remains therefore a substantial challenge (Guttman et al. 2014). A considerable number of genetic techniques have been developed for bacteria, leading to identification and further analyses of genes essential for bacteria-plant interactions in vivo (Handfield and Levesque 1999). These techniques, such as IVET (In Vitro Expression Technology), RIVET (Reverse IVET) and their modifications and adaptations, signature-tagged mutagenesis (STM) and difference fluorescent induction (DFI) as well as expression microarrays and RNAseq, are used with success to determine new bacterial virulence factors, genes involved in adaptation to the plant (micro-)environment and in bacterial fitness in specific host tissues during infection. Despite the great potential of all the mentioned techniques, they are often expensive and/or require specialized laboratory equipment and skillful technical assistance.

We propose here an inexpensive, high-throughput system to preselect Dickeya solani genes involved in bacteria-plant interaction with the employment of random mutagenesis using a Tn5 transposon containing 
inducible promoterless gusA gene (reporter gene) and screening for glucuronidase positive phenotypes in the presence of plant tissues (Fig. 1).

Pectinolytic Dickeya spp. are important necrotrophic plant pathogenic bacteria infecting a number of plant species including economically important crops such as potato (Solanum tuberosum L.) (Pérombelon 2002; Toth and Birch 2005). They are recognized among the top-ten most important plant pathogenic bacteria in agriculture (Mansfield et al. 2012). The relative importance of Dickeya spp. in the epidemiology of potato blackleg and soft rot diseases in Europe has increased since 2009 when the new virulent Dickeya species named D. solani was described in potato for the first time (Slawiak et al. 2009; van der Wolf et al. 2014). Since then the pathogen has been found in association with potato plants and tubers in many European countries and in Israel and Georgia (for review see: Toth et al. 2011). It is now generally accepted that $D$. solani causes severe rotting symptoms in potato in a range of environmental temperatures (Czajkowski et al. 2016; Golanowska et al. 2016), may survive in surface water for a relatively long time (Laurila et al. 2008) and is capable of spreading and systemically infect the host under a wide range of natural conditions (Czajkowski et al. 2012). Despite the extensive studies on the ecology of $D$. solani, still little is known about the regulation of gene expression governing the infection process (Potrykus et al. 2014), particularly during the early stages of bacteria-plant interaction leading to efficient colonization of plant tissues. The aim of this study was to develop a fast and reliable screening technique to
Fig. 1 A schematic presentation of the screening procedure. D. solani IPO2222 Tn5 mutants are generated using conjugation with Tn5 donor Escherichia coli S17 $\lambda$-pir carrying a pFAJ1819 plasmid (1) and Tn5 mutant colonies are selected on the M9 minimal medium under noninductive conditions (2). Tn5 mutants showing $\beta$ glucuronidase-negative phenotype are collected (whereas mutants presenting $\beta$ glucuronidase-positive phenotype are discarded) (3). The collected Tn5 mutants are subsequently tested in the 48-well microtiter plate assay in liquid M9 minimal medium supplemented with antibiotic and $\beta$-glucuronidase substrate - X-gluc after $48 \mathrm{~h}$ incubation at $28^{\circ} \mathrm{C}$ with shaking (120 rpm). Positive reaction, hence plant tissue-induced gene expression is visualized as a change in a medium color from whitish/transparent to blue/dark blue in the wells if the microtiter plate (5) (Fig. 2). The mutants expressing $\beta$-glucuronidase phenotype in the presence of plant tissues are selected for sequencing of the Tn5 insertion sites
1. Conjugation of E. coli S17 $\lambda$-pir pFAJ1819 and D. solani IPO2222

2. Negative selection of Tn5 mutants on agar medium under non-inductive conditions

3. Tn5 mutants showing $\beta$ glucuronidase negative phenotype are collected for further analyses

4. Microtiter plate assay with Tn5 mutants selected in the previous step in the presence of plant tissues (leaves, stems and roots)

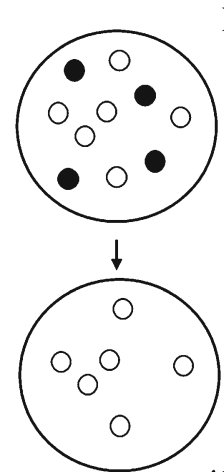

48-well $\downarrow \quad$ microtiter plate

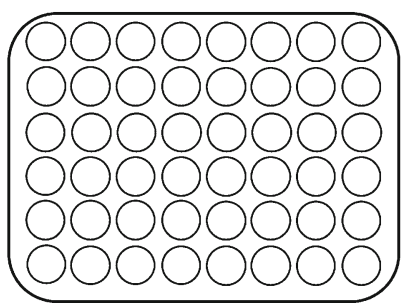

5. After 2-day incubation, Tn 5 mutants are screened for $\beta$-glucuronidase positive phenotype and selected for sequencing of the Tn5 insertion

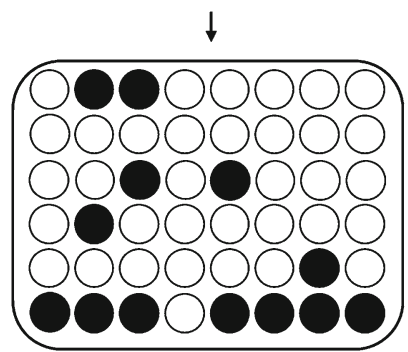


preselect candidate $D$. solani genes up-regulated in early stages of bacterial interaction with plant tissues.

To achieve this objective we selected $S$. tuberosum (primary host) and $S$. dulcamara (secondary host) plants, as they sustain the natural habitats for pectinolytic bacteria (Fikowicz-Krosko et al. 2017; Pérombelon 2002). Unless otherwise stated, standard molecular biological and microbiology methods were used for all experiments (Sambrook et al. 1989). The methodology was based on random transposon mutagenesis of $D$. solani strain IPO2222 genome with a mini-Tn5 containing promoterless gusA gene (Wilson et al. 1995). To mutate D. solani genome, conjugation of D. solani IPO2222 and Escherichia coli S17 $\lambda$-pir carrying pFAJ1819 suicide

$\mathbf{a}$

48-well microtiter plate

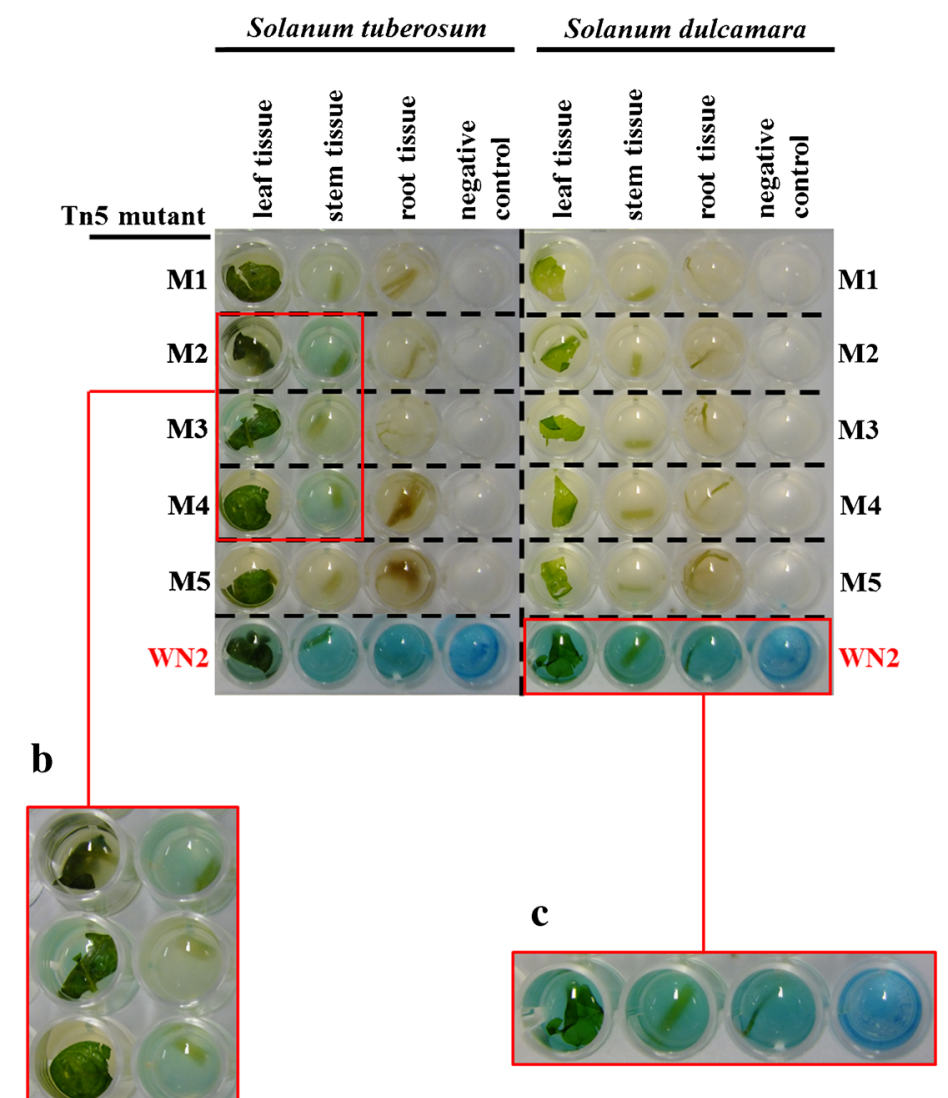

Fig. 2 Example results of the fast screening system to preselect plant tissue-induced D. solani Tn5 mutants. Solanum dulcamara and Solanum tuberosum leaf, stem and root tissue cuts of 2-5 mm in length and ca. $1 \mathrm{~cm}$ in width were individually and aseptically placed in the wells of the microtiter plate containing $500 \mu \mathrm{l}$ of bacterial growth medium (M9 containing $50 \mu \mathrm{g} \mathrm{ml} l^{-1}$ neomycine and $100 \mu \mathrm{g} \mathrm{ml}^{-1} \mathrm{X}$-gluc) per well. Such prepared wells were subsequently inoculated with $15 \mu$ l of individual $D$. solani $\operatorname{Tn} 5$ mutant cultures (M1, M2, M3, M5, M5) containing ca. $10^{9}$ colony forming units (cfu) $\mathrm{ml}^{-1}$ in M9. For control, per mutant, wells containing growth medium and inoculated with respective Tn5 mutant but without plant tissue were used. The Tn5 D. solani mutant with constitutive $\beta$-glucuronidase expression (WN2) was used as a positive control. The microtiter plates were incubated for $48 \mathrm{~h}$ at $28^{\circ} \mathrm{C}$ with shaking (120 rpm) for development of the blue

color (X-gluc degradation by $\beta$-glucuronidase), which indicated the positive reaction (up-regulation of Tn5-disrupted gene of interest in bacterial genome) (a). Magnification of the wells of the 48-well microtiter plate containing Tn5 mutant cultures induced by the presence of plant tissues (b). Mutants M2 and M4 expressed $\beta$-glucuronidase phenotype in the presence of $S$. tuberosum stem tissue, whereas mutant M3 expressed $\beta$-glucuronidase phenotype in the presence of leaf tissue, the same mutants expressed $\beta$-glucuronidase negative phenotype in the presence of S. dulcamara tested tissues. Magnification of the wells of the 48well microtiter plate containing D. solani Tn5 WN2 mutant culture expressing constitutive $\beta$-glucuronidase phenotype independent from presence of plant tissues (c). The $\beta$-glucuronidase positive phenotype was found both if wells with plant tissue cuts and in plant tissue-less control well 
vector with mini-Tn5-promoterless gusA gene (Xi et al. 1999) was performed as previously described (Czajkowski et al. 2011). After conjugation, the resulting D. solani Tn5 mutants were selected as previously described (Czajkowski et al. 2016), using M9 agar plates supplemented with $50 \mu \mathrm{g} \mathrm{ml}^{-1}$ neomycine (Sigma) and $20 \mu \mathrm{g} \mathrm{ml}^{-1} \mathrm{X}$-gluc (substrate for glucuronidase: 5-bromo4-chloro-3-indolyl-b-D-glucuronide) (GeneON). The Tn5 mutants showing lack of $\beta$-glucuronidase activity under non-inductive conditions were selected for screening with plant tissues, viz. roots, stems and leaves of $S$. tuberosum and $S$. dulcamara plants. For this, $400 \mu$ lof M9 containing $50 \mu \mathrm{g} \mathrm{ml}^{-1}$ neomycine and $100 \mu \mathrm{g} \mathrm{ml}^{-1} \mathrm{X}$-gluc was pipetted into each well of a 48 -well microtiter plate (Falcon). In vitro cultures of $S$. tuberosum and S. dulcamara cultivated and propagated on Murashige and Skoog (MS) medium (Murashige and Skoog 1962), as previously described (Rietman et al. 2014; Jones 1994; Czajkowski et al. 2015), were used as a source of plant tissue material. In vitro 2-week-old plants were aseptically removed from culture tubes following preparation of leaf, stem and root cuts of ca. $2-5 \mathrm{~mm}$ in length and ca. $1 \mathrm{~cm}$ in width. For each of the Tn5 D. solani mutant to be screened, in duplicates, leaf, stem and root cuts were analyzed. The plant cuts were individually and aseptically placed in the wells of the microtiter plate containing $500 \mu \mathrm{l}$ of bacterial growth medium (M9 containing $50 \mu \mathrm{g} \mathrm{ml}^{-1}$ neomycine and $100 \mu \mathrm{g}$ $\mathrm{ml}^{-1}$ X-gluc) per well. Such prepared wells were subsequently inoculated with $15 \mu \mathrm{l}$ of individual $D$. solani Tn5 mutant cultures containing ca. $10^{9}$ colony forming units (cfu) $\mathrm{ml}^{-1}$ in M9. For control, per mutant, wells containing growth medium and inoculated with respective Tn5 mutant but without plant tissue were used. Three Tn5 D. solani mutants (named WN1, WN2 and WN3) with constitutive glucuronidase expression were used as a positive control for glucuronidase activity as previously described (Goyer and Ullrich 2006). The microtiter plates were incubated for $48 \mathrm{~h}$ at $28{ }^{\circ} \mathrm{C}$ with shaking $(120 \mathrm{rpm})$ for development of blue color (Xgluc degradation by $\beta$-glucuronidase) which indicated the positive reaction (up-regulation of Tn5-disrupted gene of interest in bacterial genome) (Fig. 2). The experiment was repeated independently one time with the same setup. Tn5 mutants in genes up-regulated in contact with plant tissues were selected for sequencing the transposon insertion sites as previously described (Czajkowski et al. 2016). In the preliminary screening, we selected the first five hundred $D$. solani IPO2222 $\beta$ - glucuronidase negative Tn5 mutants for testing the plantinduced gene expression. From these, 12 (2.4\%), 52 $(10.4 \%)$ and $22(4.4 \%)$ of the tested mutants showed $\beta$-glucuronidase positive phenotype in contact with roots, stem and leaves of $S$. tuberosum, respectively. Example results are shown in Fig. 2.

The proposed fast screening selection of plant tissueinduced $D$. solani transposon mutants, in contrast to other methods, allows direct preselection of candidate mutants for further studies including the analyses of interactions with host and non-host plants and with various biotic and abiotic stressors.

It has to be noted here that the proposed fast screening system gives only the first preliminary selection of the plant tissue-induced candidate genes. It is therefore still needed to assess the gene expression in a quantitative manner. Likewise, it has to be stressed that this is an in vitro set-up performed with injured plant tissues not with the unbroken and real-size plants in vivo.

The main advantage is however, that this approach does not require the recovery of bacterial cells after host infection, and therefore can be considered as a genuinely fast screen for the identification of upregulated genes in plant-bacteria interactions. What is more, such Tn5 mutants may be subsequently tested against several factors, which is not the case of microarrays and RNAseq. The procedure does not require the use of expensive laboratory equipment and consumables as well as any bioinformatic or statistical tools and therefore it may be performed in virtually every microbiological laboratory.

Acknowledgements The work was financially supported by the National Science Center, Poland (Narodowe Centrum Nauki, Polska) via a research grant NCN SONATA 8 (2014/15/D/NZ9/ 00605) to Robert Czajkowski. The authors would like to express their gratitude to Prof. Titti Mariani (Department of Molecular Plant Physiology, Faculty of Science, Radboud University, Nijmegen, the Netherlands) for providing the in vitro cultures of $S$. dulcamara plants and very helpful discussions about S. dulcamara cultivation, Wioletta Lisicka (University of Gdansk, Gdansk, Poland) for generation of D. solani IPO2222 Tn5 WN1, WN2 and WN3 mutants and Magdalena Rajewska (University of Gdansk, Gdansk, Poland) for her comments on the manuscript and her editorial work.

Open Access This article is distributed under the terms of the Creative Commons Attribution 4.0 International License (http:// creativecommons.org/licenses/by/4.0/), which permits unrestricted use, distribution, and reproduction in any medium, provided you give appropriate credit to the original author(s) and the source, provide a link to the Creative Commons license, and indicate if changes were made. 


\section{References}

Czajkowski, R., Krzyzanowska, D., Karczewska, J., Atkinson, S., Przysowa, J., Lojkowska, E., et al. (2011). Inactivation of AHLs by Ochrobactrum sp. A44 depends on the activity of a novel class of AHL acylase. Environmental Microbiology Reports, 3, 59-68. doi:10.1111/j.1758-2229.2010.00188.x.

Czajkowski, R., de Boer, W. J., van der Zouwen, P. S., Kastelein, P., Jafra, S., de Haan, E. G., et al. (2012). Virulence of 'Dickeya solani' and Dickeya dianthicola biovar-1 and -7 strains on potato (Solanum tuberosum). Plant Pathology, 62, 597-610. doi:10.1111/j.1365-3059.2012.02664.x.

Czajkowski, R., van der Wolf, J. M., Krolicka, A., Ozymko, Z., Narajczyk, M., Kaczynska, N., et al. (2015). Salicylic acid can reduce infection symptoms caused by Dickeya solani in tissue culture grown potato (Solanum tuberosum L.) plants. European Journal of Plant Pathology, 141, 545-558. doi:10.1007/s10658-014-0561-z.

Czajkowski, R., Kaczyńska, N., Jafra, S., Narajczyk, M., \& Lojkowska, E. (2016). Temperature-responsive genetic loci in pectinolytic plant pathogenic Dickeya solani. Plant Pathology. doi:10.1111/ppa.12618. early view.

Fikowicz-Krosko, J., Wszalek-Rozek, K., Smolarska, A., \& Czajkowski, R. (2017). First report of isolation of soft rot Pectobacterium carotovorum subsp. carotovorum from symptomless bittersweet nightshade occuing in rural area of Poland. Journal of Plant Pathology, 99, 287-304. doi:10.4454/jpp.v99i1.3772.

Golanowska, M., Kielar, J., \& Lojkowska, E. (2016). The effect of temperature on the phenotypic features and the maceration ability of Dickeya solani strains isolated in Finland, Israel and Poland. European Journal of Plant Pathology 1-15. doi:10.1007/s10658-016-1044-1.

Goyer, C., \& Ullrich, M. (2006). Identification of lowtemperature-regulated genes in the fire blight pathogen Erwinia amylovora. Canadian Journal of Microbiology, 52, 468-475. doi:10.1139/w05-153.

Guttman, D. S., McHardy, A. C., \& Schulze-Lefert, P. (2014). Microbial genome-enabled insights into plant-microorganism interactions. Nature Reviews Genetics, 15, 797-813.

Handfield, M., \& Levesque, R. C. (1999). Strategies for isolation of in vivo expressed genes from bacteria. FEMS Microbiology Reviews, 23, 69-91. doi:10.1111/j.15746976.1999.tb00392.x.

Jones, M. G. K. (1994). In vitro culture of potato. In I. K. Vasil \& T. A. Thorpe (Eds.), Plant cell and tissue culture (pp. 363378). Dordrecht: Springer Netherlands.

Laurila, J., Ahola, V., Lehtinen, A., Joutsjoki, T., Hannukkala, A., Rahkonen, A., et al. (2008). Characterization of Dickeya strains isolated from potato and river water samples in Finland. European Journal of Plant Pathology, 122, 213225. doi:10.1007/s10658-008-9274-5.

Mansfield, J., Genin, S., Magori, S., Citovsky, V., Sriariyanum, M., Ronald, M., et al. (2012). Top 10 plant pathogenic bacteria in molecular plant pathology. Molecular Plant Pathology, 13, 614-629. doi:10.1111/j.1364-3703.2012.00804.x.
Murashige, T., \& Skoog, F. (1962). A revised medium for rapid growth and bioassays with tobacco tissue cultures. Physiologia Plantarum, 15, 473-497. doi:10.1111/j.13993054.1962.tb08052.x.

Pérombelon, M. C. M. (2002). Potato diseases caused by soft rot erwinias: An overview of pathogenesis. Plant Pathology, 51, 1-12. doi:10.1046/j.0032-0862.2001.

Potrykus, M., Golanowska, M., Hugouvieux-Cotte-Pattat, N., \& Lojkowska, E. (2014). Regulators involved in Dickeya solani virulence, genetic conservation and functional variability. Molecular Plant-Microbe Interactions, 27, 700-711. doi:10.1094/MPMI-09-13-0270-R.

Rietman, H., Finkers, R., Evers, L., Zouwen, P. S., Wolf, J. M., \& Visser, R. G. F. (2014). A stringent and broad screen of Solanum spp. tolerance against Erwinia bacteria using a petiole test. American Journal of Potato Research, 91, 204 215. doi:10.1007/s12230-013-9339-7.

Sambrook, J., Fritsch, E. F., \& Maniatis, T. (1989). Molecular cloning: a laboratory manual. - 2nd ed. New York, USA: Cold Spring Harbor Laboratory Press.

Slawiak, M., van Beckhoven, J. R. C. M., Speksnijder, A. G. C. L., Czajkowski, R., Grabe, G., \& van der Wolf, J. M. (2009). Biochemical and genetical analysis reveal a new clade of biovar 3 Dickeya spp. strains isolated from potato in Europe. European Journal of Plant Pathology, 125, 245261. doi:10.1007/s10658-009-9479-2.

Toth, I. K., \& Birch, P. R. J. (2005). Rotting softly and stealthily. Current Opinion in Plant Biology, 8, 424-429. doi:10.1016/j.pbi.2005.04.001.

Toth, I. K., van der Wolf, J. M., Saddler, G., Lojkowska, E., Hélias, V., Pirhonen, M., et al. (2011). Dickeya species: An emerging problem for potato production in Europe. Plant Pathology, 60, 385-399. doi:10.1111/j.1365-3059.2011.02427.x.

Vidaver, A. K., \& Lambrecht, P. A. (2004). Bacteria as plant pathogens. The Plant Health Instructor. The American Phytopathological Society (APS) online publication (website: http://www.apsnet. org/edcenter/intropp/PathogenGroups/Pages/Bacteria. aspx).

Wilson, K. J., Sessitsch, A., Corbo, J. C., Giller, K. E., Akkermans, A. D. L., \& Jefferson, R. A. (1995). $\beta-$ Glucuronidase (GUS) transposons for ecological and genetic studies of rhizobia and other gram-negative bacteria. Microbiology, 141, 1691-1705. doi:10.1099 /13500872-141-7-1691.

van der Wolf, J. M., Nijhuis, E. H., Kowalewska, M. J., Saddler, G. S., Parkinson, N., Elphinstone, J. G., et al. (2014). Dickeya solani sp. nov., a pectinolytic plant pathogenic bacterium isolated from potato (Solanum tuberosum). International Journal of Systematic and Evolutionary Microbiology, 64, 768-774. doi:10.1099/ijs.0.052944-0.

Xi, C., Lambrecht, M., Vanderleyden, J., \& Michiels, J. (1999). Bi-functional $g f p$-and gusA-containing mini-Tn5 transposon derivatives for combined gene expression and bacterial localization studies. Journal of Microbiological Methods, 35, 85-92. 